\title{
A validated tumor control probability model based on a meta-analysis of low, intermediate, and high-risk prostate cancer patients treated by photon, proton, or carbon-ion radiotherapy
}

Citation for published version (APA):

Walsh, S., Roelofs, E., Kuess, P., Lambin, P., Jones, B., Georg, D., \& Verhaegen, F. (2016). A validated tumor control probability model based on a meta-analysis of low, intermediate, and high-risk prostate cancer patients treated by photon, proton, or carbon-ion radiotherapy. Medical Physics, 43(2), 734-747. https://doi.org/10.1118/1.4939260

Document status and date:

Published: 01/02/2016

DOI:

$10.1118 / 1.4939260$

Document Version:

Publisher's PDF, also known as Version of record

Document license:

Taverne

Please check the document version of this publication:

- A submitted manuscript is the version of the article upon submission and before peer-review. There can be important differences between the submitted version and the official published version of record. People interested in the research are advised to contact the author for the final version of the publication, or visit the DOI to the publisher's website.

- The final author version and the galley proof are versions of the publication after peer review.

- The final published version features the final layout of the paper including the volume, issue and page numbers.

Link to publication

\footnotetext{
General rights rights.

- You may freely distribute the URL identifying the publication in the public portal. please follow below link for the End User Agreement:

www.umlib.nl/taverne-license

Take down policy

If you believe that this document breaches copyright please contact us at:

repository@maastrichtuniversity.nl

providing details and we will investigate your claim.
}

Copyright and moral rights for the publications made accessible in the public portal are retained by the authors and/or other copyright owners and it is a condition of accessing publications that users recognise and abide by the legal requirements associated with these

- Users may download and print one copy of any publication from the public portal for the purpose of private study or research.

- You may not further distribute the material or use it for any profit-making activity or commercial gain

If the publication is distributed under the terms of Article $25 \mathrm{fa}$ of the Dutch Copyright Act, indicated by the "Taverne" license above, 

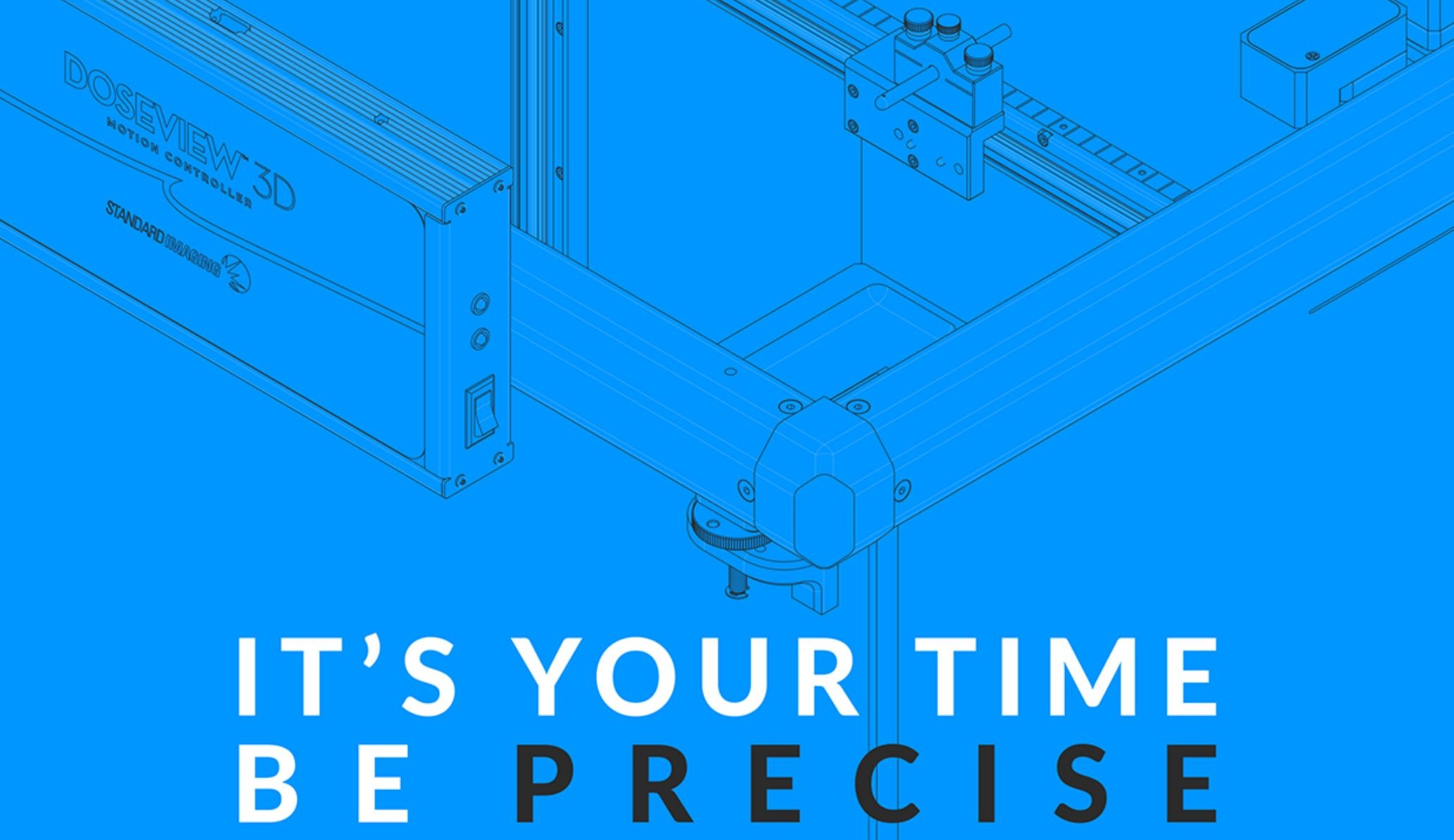

STANDARDIMAGING

Every day we spend our time optimizing ways to make QA easy and reliable.

Ask us how our solutions can benefit you. 


\title{
A validated tumor control probability model based on a meta-analysis of low, intermediate, and high-risk prostate cancer patients treated by photon, proton, or carbon-ion radiotherapy
}

\author{
Seán Walsha) \\ Department of Radiation Oncology (MAASTRO), GROW-School for Oncology and Developmental Biology, \\ Maastricht University Medical Center (MUMC+), Maastricht 6229 ET, The Netherlands \\ and Department of Oncology, Gray Institute for Radiation Oncology and Biology, University of Oxford, \\ Oxford OX3 $7 D Q$, United Kingdom
}

\section{Erik Roelofs}

Department of Radiation Oncology (MAASTRO), GROW-School for Oncology and Developmental Biology, Maastricht University Medical Center (MUMC+), Maastricht 6229 ET, The Netherlands

\section{Peter Kuess}

Department of Radiation Oncology and Christian Doppler Laboratory for Medical Radiation Research for Radiation Oncology, Medical University of Vienna, Vienna 1090, Austria

Philippe Lambin

Department of Radiation Oncology (MAASTRO), GROW-School for Oncology and Developmental Biology, Maastricht University Medical Center (MUMC+), Maastricht 6229 ET, The Netherlands

\section{Bleddyn Jones}

Department of Oncology, Gray Institute for Radiation Oncology and Biology, University of Oxford, Oxford $O X 37 D Q$, United Kingdom

\section{Dietmar Georg}

Department of Radiation Oncology and Christian Doppler Laboratory for Medical Radiation Research for Radiation Oncology, Medical University of Vienna, Vienna 1090, Austria

\section{Frank Verhaegen}

Department of Radiation Oncology (MAASTRO), GROW-School for Oncology and Developmental Biology, Maastricht University Medical Center (MUMC+), Maastricht 6229 ET, The Netherlands and Medical Physics Unit, Department of Oncology, McGill University, Montréal, Québec H4A 3J1, Canada

(Received 17 April 2015; revised 6 November 2015; accepted for publication 19 December 2015; published 14 January 2016)

Purpose: A fully heterogeneous population averaged mechanistic tumor control probability (TCP) model is appropriate for the analysis of external beam radiotherapy (EBRT). This has been accomplished for EBRT photon treatment of intermediate-risk prostate cancer. Extending the TCP model for low and high-risk patients would be beneficial in terms of overall decision making. Furthermore, different radiation treatment modalities such as protons and carbon-ions are becoming increasingly available. Consequently, there is a need for a complete TCP model.

Methods: A TCP model was fitted and validated to a primary endpoint of 5-year biological no evidence of disease clinical outcome data obtained from a review of the literature for low, intermediate, and high-risk prostate cancer patients (5218 patients fitted, 1088 patients validated), treated by photons, protons, or carbon-ions. The review followed the preferred reporting item for systematic reviews and meta-analyses statement. Treatment regimens include standard fractionation and hypofractionation treatments. Residual analysis and goodness of fit statistics were applied.

Results: The TCP model achieves a good level of fit overall, linear regression results in a $p$-value of $<0.00001$ with an adjusted-weighted- $R^{2}$ value of 0.77 and a weighted root mean squared error (wRMSE) of $1.2 \%$, to the fitted clinical outcome data. Validation of the model utilizing three independent datasets obtained from the literature resulted in an adjusted-weighted- $R^{2}$ value of 0.78 and a wRMSE of less than $1.8 \%$, to the validation clinical outcome data. The weighted mean absolute residual across the entire dataset is found to be $5.4 \%$.

Conclusions: This TCP model fitted and validated to clinical outcome data, appears to be an appropriate model for the inclusion of all clinical prostate cancer risk categories, and allows evaluation of current EBRT modalities with regard to tumor control prediction. (c) 2016 American Association of Physicists in Medicine. [http://dx.doi.org/10.1118/1.4939260]

Key words: proton, carbon-ion, prostate, TCP, RBE 


\section{INTRODUCTION}

Prostate cancer has the second highest incident rate and is the fifth most mortal cancer in men. ${ }^{1}$ The highest incidence rates are in Western and Northern Europe as well as Northern America, principally due to prostate specific antigen (PSA) testing and subsequent biopsy (Gleason score) being more widespread. In widely screened populations such as Northern America, the high-risk cohort represents only $15 \%$ of patients, and a higher percentage will occur in less heavily screened populations because screening identifies earlier presymptomatic stages of the condition. ${ }^{2}$ External beam radiation therapy (EBRT) is one of the primary treatment options to treat prostate cancer. ${ }^{3}$ Advances in technology have led to the development of three physically and potentially different EBRT treatment modalities, viz., photon (X-EBRT), proton (P-EBRT), and carbon-ion (C-EBRT) therapy.

Previous radiobiological modeling studies, both theoretical and fitting exercises, have focused on X-EBRT (Refs. 4-15) (of which a full and detailed review is deemed beyond the scope of this work), an exception to this is a fitting study $^{16}$ where a tumor control probability (TCP) model ${ }^{17}$ was fit to data from lung cancer patients treated by C-EBRT (Refs. 18-20) and a theoretical study exploring the upper and lower bounds of the probability of cure in the context of $\mathrm{C}$ EBRT. ${ }^{21}$ However, to our knowledge, no TCP model has been fit to prostate cancer outcome data treated by either P-EBRT or C-EBRT. This work presents a TCP model ${ }^{22}$ applicable to all EBRT modalities treating low, intermediate, and high-risk prostate cancer patients and shows the capability of the model to accurately predict TCP using biologically realistic input parameters for radiosensitivity and clonogen density, as well as clonogen density distribution and tumor hypoxia status obtained from the fit presented below.

\section{MATERIALS AND METHODS}

\section{A. The data used to fit the tumor control probability model}

The preferred reporting item for systematic reviews and meta-analyses (PRISMA) checklist was utilized. A search of the ScienceDirect database was performed in December 2014. Inclusion criterion was defined as papers that reported the percentage success rate of 5-year biological no evidence of disease (bNED - a surrogate for the probability of cure) in relation to low, intermediate, or high-risk prostate cancer patients treated by X-EBRT, P-EBRT, or C-EBRT. The use of androgen deprivation therapy (ADT) was noted. The keyword "prostate cancer" with subsearch criteria of "proton therapy" or "carbon-ion" or "biochemical" or "bNED" was used. Seven studies comprising 5218 patients treated between 1991 and 2009 were deemed eligible, ${ }^{23-28}$ see Table I. The quality of evidence ranges from level-I (a properly designed randomized controlled trial) to level-II (a well-designed cohort analytic study) according to the United States preventive services task force (www.uspreventiveservicestaskforce.org). Data are available at doi:10.17195/candat.2015.10.8.

TABLE I. Clinical outcome dataset for fitting the TCP model.

\begin{tabular}{|c|c|c|c|c|c|c|c|}
\hline Pats No. & Modality & $d[\mathrm{~Gy}(E)]$ & $D[\mathrm{~Gy}(E)]$ & 5-year bNED $(\%)$ & ADT & Risk & References \\
\hline 362 & X-EBRT & 1.8 & 81.0 & 95 (PCC) & Yes $^{\mathrm{a}}$ & Low-comb & Kollmeier et al. (Ref. 27) \\
\hline 525 & X-EBRT & 1.8 & 81.0 & 89 (PCC) & Yes $^{\mathrm{a}}$ & Int-comb & Kollmeier et al. (Ref. 27) \\
\hline 412 & X-EBRT & 1.8 & 81.0 & 68 (PCC) & Yes $^{\mathrm{a}}$ & High-comb & Kollmeier et al. (Ref. 27) \\
\hline 111 & X-EBRT/P-EBRT & 1.8 & 70.2 & 83 (ASTRO) & No & Low-comb & Zietman et al. (Ref. 29) \\
\hline 116 & X-EBRT/P-EBRT & 1.8 & 79.2 & 97 (ASTRO) & No & Low-comb & Zietman et al. (Ref. 29) \\
\hline 68 & X-EBRT/P-EBRT & 1.8 & 70.2 & 75 (ASTRO) & No & Int-comb & Zietman et al. (Ref. 29) \\
\hline 61 & X-EBRT/P-EBRT & 1.8 & 79.2 & 87 (ASTRO) & No & Int-comb & Zietman et al. (Ref. 29) \\
\hline 606 & P-EBRT ${ }^{\mathrm{b}}$ & 2.0 & 74.0 & 84 (ASTRO) & No & Low-PSA & Slater et al. (Ref. 25) \\
\hline 204 & P-EBRT ${ }^{b}$ & 2.0 & 74.0 & 82 (ASTRO) & No & Low-Glea & Slater et al. (Ref. 25) \\
\hline 339 & P-EBRT ${ }^{b}$ & 2.0 & 74.0 & 65 (ASTRO) & No & Int-PSA & Slater et al. (Ref. 25) \\
\hline 868 & P-EBRT ${ }^{b}$ & 2.0 & 74.0 & 77 (ASTRO) & No & Int-Glea & Slater et al.(Ref. 25) \\
\hline 133 & P-EBRT ${ }^{b}$ & 2.0 & 74.0 & 48 (ASTRO) & No & High-PSA & Slater et al. (Ref. 25) \\
\hline 86 & P-EBRT ${ }^{b}$ & 2.0 & 74.0 & 50 (ASTRO) & No & High-Glea & Slater et al. (Ref. 25) \\
\hline 89 & P-EBRT & 2.0 & 78.0 & 99 (PCC) & Yes $^{\mathrm{a}}$ & Low-comb & Mendenhall et al. (Ref. 23) \\
\hline 82 & P-EBRT & 2.0 & 80.0 & 99 (PCC) & Yes $^{\mathrm{a}}$ & Int-comb & Mendenhall et al. (Ref. 23) \\
\hline 40 & P-EBRT & 2.0 & 78.0 & 76 (PCC) & Yes & High-comb & Mendenhall et al. (Ref. 23) \\
\hline 37 & C-EBRT & 3.3 & 66.0 & 100 (ASTRO) & No & Low-comb & Tsuji et al. (Ref. 24) \\
\hline 164 & C-EBRT & 3.3 & 66.0 & 81 (ASTRO) & Yes & High-comb & Tsuji et al. (Ref. 24) \\
\hline 33 & C-EBRT & 3.3 & 66.0 & 87 (PCC) & No & Low-comb & Ishikawa et al. (Ref. 28) \\
\hline 142 & C-EBRT & 3.3 & 66.0 & 88 (PCC) & Yes & High-comb & Ishikawa et al. (Ref. 28) \\
\hline 466 & C-EBRT & 3.3 & 66.0 & 90 (PCC) & Yes & Low/int/high-comb ${ }^{c}$ & Okada et al. (Ref. 26) \\
\hline 274 & C-EBRT & 3.6 & 57.6 & 89 (PCC) & Yes & Low/int/high-comb ${ }^{c}$ & Okada et al. (Ref. 26) \\
\hline
\end{tabular}

${ }^{\mathrm{a}} \mathrm{A}$ proportion of patients received ADT.

${ }^{\mathrm{b}} \mathrm{A}$ small proportion of patients also received X-EBRT.

${ }^{\mathrm{c}}$ The majority of patients were high-risk and were thus fit as a hybrid of intermediate and high-risk. Comb is defined as satisfying any dual combination of PSA, Gleason score, or clinical staging to determine risk. bNED is defined by either the American Society for Therapeutic Radiology and Oncology (ASTRO-three consecutive PSA rises post the PSA nadir) or the Phoenix Consensus Conference (PCC $-2 \mathrm{ng} / \mathrm{ml}$ PSA rise above the PSA nadir) definition of biochemical failure. 


\section{B. The tumor control probability model}

The TCP model uses the linear-quadratic (LQ) model of radiation effect coupled with Poisson statistics, ${ }^{22}$ a modified version of that originally proposed by Munro and Gilbert. ${ }^{30}$ The LQ model predicts the surviving fraction $S(D)$ of a population of cells exposed to a total uniform dose $D$, where $D$ is comprised of $n$ fractions of uniform dose $d$. The linear and quadratic coefficients of the LQ model are $\alpha$ and $\beta$, respectively, describing inherent radiosensitivity. Conventionally, $\alpha$ is linked with direct lethal damage and $\beta$ is linked with repairable sublethal damage, ${ }^{31}$

$$
S(D)=\exp \left[-\alpha n d-\beta n d^{2}\right] .
$$

The fully heterogeneous population averaged mechanistic TCP model is obtained from Eq. (1) by assuming that $\alpha$ and $\beta$ are distributed normally and independently among prostatic tumors within the patient population, characterized by the average values $\bar{\alpha}, \bar{\beta}$ and their standard deviations $\sigma_{\alpha}, \sigma_{\beta}$ within the patient distribution,

$$
\begin{aligned}
\mathrm{TCP}= & \frac{1}{2 \pi \sigma_{\alpha} \sigma_{\beta}} \iint_{\alpha, \beta} \exp \left[-N_{0} S(D)\right] \\
& \times \exp \left[-\frac{(\alpha-\bar{\alpha})^{2}}{2 \sigma_{\alpha}{ }^{2}}-\frac{(\beta-\bar{\beta})^{2}}{2 \sigma_{\beta}{ }^{2}}\right] \mathrm{d} \alpha \mathrm{d} \beta .
\end{aligned}
$$

Here, $N_{0}$ is the initial clonogen sum. TCP theory stems from the postulation that control is only attained if zero clonogens survive. ${ }^{32}$ Many studies have utilized the concept of the dominant intraprostatic lesion (DIL) to define the volume within the clinical target volume (CTV) most closely associated with prostate cancer. ${ }^{33-38}$ This concept of clonogen density distribution has been employed in this modeling study via distinct clonogen density values, $P_{\mathrm{CTV}}$ and $P_{\mathrm{DIL}}$, equal to $10^{5} \mathrm{~cm}^{-3}$ and $10^{6} \mathrm{~cm}^{-3}$, respectively. The DIL volume is assumed to be $X \%$ of the total CTV volume. The value for the total initial clonogen number is given by

$$
N_{0}=\left(\frac{(100-X) P_{\mathrm{CTV}}+X P_{\mathrm{DIL}}}{100}\right) \text { Volume }_{\mathrm{CTV}} .
$$

An average volume for the CTV (prostate) of $36 \mathrm{~cm}^{3}$ was used for low and intermediate-risk patients ${ }^{22}$ while an average volume for the CTV (prostate and seminal vesicles) of $72 \mathrm{~cm}^{3}$ was used for high-risk patients, ${ }^{39}$ both of these values also agree with local clinical measurements. Because the TCP model presented in Eq. (2) is analytically intractable it is estimated through numerical methods ${ }^{17}$ using

$$
\mathrm{TCP}=\left(\frac{1}{k}\right) \sum_{i=1}^{k}\left(\exp \left[-N_{0} S(D)_{k}\right]\right) .
$$

Here, $k$ signifies clusters of patients, each with a distinct radiosensitivity. The modeling process is carried out computationally by selecting $\alpha$ and $\beta$ from independent Gaussian distributions; the values for $\alpha$ and $\beta$ are used as inputs for Eq. (4) and summed over the range, $k$. The precision of the TCP model is determined by the size of $k$ and was set to $5 \times 10^{5}$ for each Gaussian distribution, excluding negative values. This ensures sufficient precision and convergence of the TCP model. The effect of hypoxia on cell survival is substantial. ${ }^{40}$ Consequently, the patient population partial pressure of oxygen (PO2) status was incorporated into the model through two separate groups. Assuming that the distributions of DILs and hypoxia are independent, the proportion of the total initial number of clonogens defined as the hypoxic fraction and the aerobic fraction in this modeling exercise was $Y \%$ and $100-Y \%$, respectively. This dependence on PO2 is described by the oxygen enhancement ratio (OER),

$$
\alpha_{\text {hyp }}=\frac{\alpha_{\text {aero }}}{\mathrm{OER}}, \quad \beta_{\text {hyp }}=\frac{\beta_{\text {aero }}}{\mathrm{OER}^{2}} .
$$

The OER is dependent on the linear energy transfer (LET) of radiation ${ }^{41}$ and must be modified when modeling C-EBRT.

\section{C. Incorporating relative biological effectiveness (RBE) into the tumor control probability model}

Higher and lower LET radiations can be intercompared by estimation of the RBE, defined as the ratio of lower and higher LET doses required to produce a given biologic effect, ${ }^{42}$ such as $S(D)$ described by Eq. (1),

$$
\begin{aligned}
& S(D)_{l}=\exp \left[-\alpha_{l} n d_{l}-\beta_{l} n d_{l}^{2}\right], \\
& S(D)_{h}=\exp \left[-\alpha_{h} n d_{h}-\beta_{h} n d_{h}^{2}\right], \\
& \mathrm{RBE}=\frac{d_{l}}{d_{h}} .
\end{aligned}
$$

Conventionally, dose for ions is prescribed as $\mathrm{Gy}(E)$ by scaling the physical dose by the RBE, for which clinical values of 1.1 and 3.0 are used for P-EBRT and C-EBRT, respectively. ${ }^{43}$ The studies included in our meta-analysis followed this convention. However, RBE varies with LET, dose, and radiosensitivity. ${ }^{44}$ Only some of these complex biophysical interactions were included and purportedly accounted for in the treatment planning of the studies included in our meta-analysis. Therefore, a LQ-based RBE model ${ }^{44-46}$ which accounts for the dependence of RBE on LET, dose, and radiosensitivity was employed to estimate $\mathrm{RBE}_{\min }$ (asymptotic value of RBE at $d_{h}=\infty \mathrm{Gy}$ ) and $\mathrm{RBE}_{\max }$ (asymptotic value of $\mathrm{RBE}$ at $d_{h}=0 \mathrm{~Gy}$ ) for both P-EBRT and C-EBRT,

$$
\begin{aligned}
& \mathrm{RBE} \\
& =\frac{-(\alpha / \beta)_{l}+\sqrt{(\alpha / \beta)_{l}^{2}+4 d_{h}\left[(\alpha / \beta)_{l} \mathrm{RBE}_{\max }+\mathrm{RBE}_{\min }^{2} d_{h}\right]}}{2 d_{h}} \\
& \mathrm{RBE}_{\max }=\frac{\alpha_{h}}{\alpha_{l}} \\
& \mathrm{RBE}_{\min }=\sqrt{\frac{\beta_{h}}{\beta_{l}}}
\end{aligned}
$$

\section{D. Fitting the tumor control probability model}

Values obtained from a previous fit of this TCP model to X-EBRT treatments of intermediate-risk patients ${ }^{22}$ were utilized here as fixed values: $\bar{\alpha}=0.25 \mathrm{~Gy}^{-1}, \bar{\alpha} / \bar{\beta}=2.48 \mathrm{~Gy}$, $\sigma_{\alpha}=11.3 \%, \sigma_{\beta}=12.9 \%$, DIL volume $=10 \%$, hypoxic 
fraction $=15 \%$, and OER $=1.75$. This approach $^{47}$ enables fitting of the DIL volume and the hypoxic fraction for low and high-risk prostate cancer patients as well as the $\mathrm{RBE}_{\min }$ and $\mathrm{RBE}_{\max }$ of both P-EBRT and C-EBRT along with the modification of the OER in the case of C-EBRT due to LET.

The TCP model is analytically intractable and consequently standard fitting techniques are inappropriate, and the model was therefore fitted using the Nelder-Mead (NM) simplex algorithm ${ }^{48}$ (the same algorithm used in the previous fit of this TCP model to X-EBRT treatments of intermediate-risk patients ${ }^{22}$ ). The NM simplex algorithm is a robust method for determining a local minimum of a function with several variables. ${ }^{49,50}$ For nine variables-DIL volume (high and low), hypoxic fraction (high and low), $\mathrm{RBE}_{\min }$ (P-EBRT and C-EBRT) and $\mathrm{RBE}_{\max }$ (P-EBRT and C-EBRT), and the modification of the OER in the case of C-EBRT due to LETa simplex is a decayotton and the technique is a pattern search that equates function values at the ten vertices of the simplex. The worst vertex is excluded and substituted with a new vertex, and a new simplex is created and the search continues. The algorithm transforms the simplex repetitively based upon certain conditions until the termination test is fulfilled. A single iteration of the NM method comprises the following three steps.

1. Ordering: define the indices of the vertices from worst to best, respectively, in the present operational simplex. $f\left(x_{n+1}\right)>\cdots>f\left(x_{2}\right)>f\left(x_{1}\right)>f\left(x_{0}\right)$ (i.e., $x_{n+1}$ is the worst vertex).

2. Centroid: compute the centroid $\bar{x}$ of the best face- the one opposite the worst vertex, $\bar{x}=(1 / n) \sum_{i} x_{i}$.

3. Transformation: calculate the new operational simplex from the present one. Initially, attempt to substitute only the worst vertex $x_{n+1}$ with a superior vertex by means of reflection, expansion, or contraction with respect to the best face. If this succeeds, the superior vertex becomes part of the new operational simplex. If this fails, the entire simplex contracts toward the best vertex $x_{0}$. In this situation, $n$ new vertices are computed. All test vertices lie on the line defined by $x_{n+1}$ and $\bar{x}$. To minimize the possibility that the algorithm could converge to a suboptimal local solution instead of an optimum global minimum, the algorithm began its pattern search for the best possible solution with 2359296 initial guesses. These starting points cover the known realistic range of DIL volume, hypoxic fraction, $\mathrm{RBE}_{\min }$ and $\mathrm{RBE}_{\max }$, and the modification of the OER in the case of C-EBRT due to LET. ${ }^{12,37,38,41,51-54}$ The algorithm was employed to minimize the sum of the absolute residuals produced by the TCP model, weighted to the number of patients per data point.

\section{E. Statistical evaluation of the goodness of fit}

To quantify the accuracy of the TCP model, residuals, defined as the difference between the specific clinical outcome and the specific predicted TCP value, and linear regression goodness of fit statistics, weighted to the number of patients per data point to avoid bias, were used. The optimum model fit is that which delivers the lowest weighted mean absolute residual (wMAR), the lowest weighted root mean squared error (wRMSE), and the highest adjusted-weighted$R^{2}$ (coefficient of determination). These three statistical metrics inhabit the same solution space due to weighting the optimization process.

\section{F. Validation of the tumor control probability model}

To further evaluate and validate the TCP model, three independent X-EBRT datasets comprising 27 data points and consisting in total of 1088 low, intermediate, and high-risk patients, acquired from the literature, ${ }^{55-57}$ were utilized. After the fitting process was complete, the model was benchmarked against these datasets. These datasets were previously used to fit other TCP models and were thus deemed suitable for validation, see the Appendix, Tables III and IV.

\section{RESULTS}

The optimized biological input parameters of the TCP model obtained from the fit are listed in Table II. The magnitude of the hypoxic fraction and the volume of the DIL are both found to increase with risk group. The range of variation in RBE is found to increase from P-EBRT to CEBRT. The OER of 1.75 for X-EBRT and P-EBRT is predicted to be reduced by $14.4 \%$ [14.0\%-19.6\%] in the case of C-EBRT due to high LET.

Linear regression of the model's predictions, compared to the fitted and validation clinical outcome datasets, is displayed in Fig. 1 and resulted in an adjusted-weighted$R^{2}$ value of $0.77-0.78$ and a wRMSE of $1.2 \%-1.8 \%$, respectively. The model is highly significant with a $p$-value of $<1.0 \times 10^{-6}$ in both the fitted and validation datasets. The capability of the TCP model across multiple modalities, risk groups, and fractionation regimes is compatible with a robust radiobiological framework.

Figure 2 displays the residuals of the TCP model calculated from both the fit and validation clinical outcome datasets. The model is found to produce maximum and minimum residuals of $44 \%$ and $0 \%$, respectively. The major residuals correspond to the data points associated with small patient numbers, and

TABLE II. Optimization of the input parameters for the TCP model.

\begin{tabular}{lcc}
\hline \hline Risk group & DIL volume $(\%)$ & Hypoxic fraction $(\%)$ \\
\hline Low & $7.4^{\mathrm{a}}[3.5-8.9]$ & $5.6^{\mathrm{a}}[5.2-6.8]$ \\
Intermediate & $10.0^{\mathrm{b}}$ & $15.0^{\mathrm{b}}$ \\
High & $20.9^{\mathrm{a}}[10.3-21.5]$ & $23.8^{\mathrm{a}}[23.3-34.4]$ \\
Treatment modality & $\mathrm{RBE}_{\min }$ & $\mathrm{RBE}_{\max }$ \\
\hline X-EBRT & $\mathrm{N} / \mathrm{A}$ & $\mathrm{N} / \mathrm{A}$ \\
P-EBRT & $1.0^{\mathrm{a}}[1.0-1.1]$ & $1.2^{\mathrm{a}}[1.1-1.3]$ \\
C-EBRT & $1.5^{\mathrm{a}}[1.4-1.8]$ & $3.9^{\mathrm{a}}[3.7-5.3]$ \\
\hline \hline
\end{tabular}

${ }^{a}$ The value was obtained from the current fit of the TCP model.

${ }^{\mathrm{b}}$ The value was obtained from a previous fit of the TCP model. 

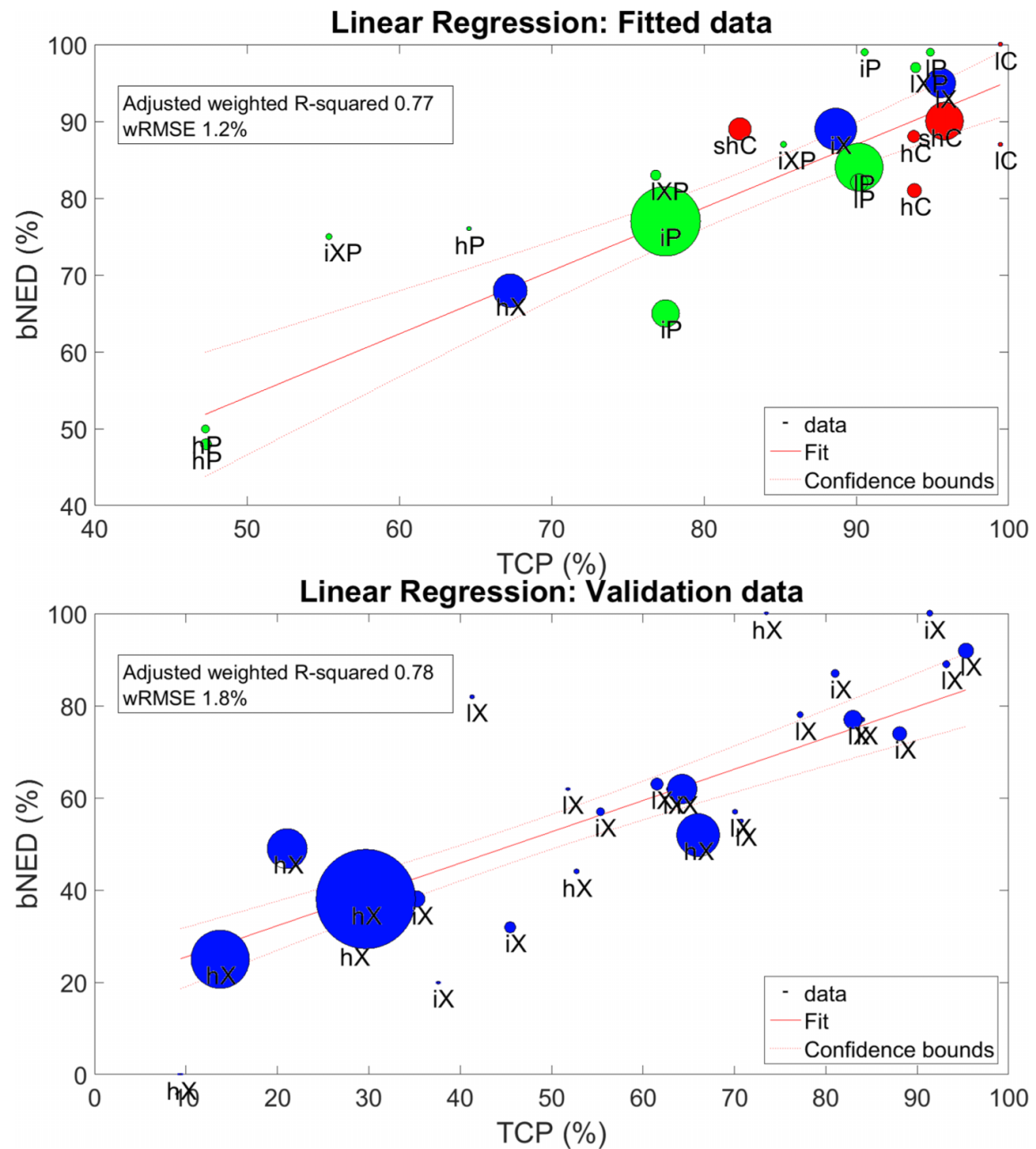

FIG. 1. Linear regression for the fit and validation of the TCP model: Each data point has a subscript indicating risk group ( $l$ : low, $i$ : intermediate, and $h$ : high) and treatment modality ( $X$ : photon, $P$ : proton, and $C$ : carbon-ion). The circular area surrounding each data point has been scaled to reflect the number of patients associated with that data point. The data express a high degree of correlation between the projected TCP outcomes and the reported clinical outcomes.

vice versa. The wMAR across the entire dataset is found to be $5.4 \%$.

The sensitivity of the biological solution space and therefore fitted model parameters listed in Table II is dependent upon the multiparametric construction of the TCP model. Several permutations of DIL volume, hypoxic fraction, $\mathrm{RBE}_{\min }, \mathrm{RBE}_{\max }$, and OER exist which provide a low wRMSE (in combination with the fixed values for $\bar{\alpha}, \bar{\alpha} / \bar{\beta}, \sigma_{\alpha}$, and $\left.\sigma_{\beta}\right)$. This relationship is illustrated in Fig. 3, providing an awareness of the possible permutations and range of the biological solution space. Using the radiosensitivity values employed here, the model always achieves a wRMSE of $<3 \%$ and adjusted-weighted- $R^{2}>0.3$ for any permutation of DIL volume, hypoxic fraction, $\mathrm{RBE}_{\min }, \mathrm{RBE}_{\max }$, and OER.

\section{DISCUSSION}

\section{A. The accuracy and performance of the tumor control probability model}

The TCP model successfully predicts the 5-year bNED clinical outcomes for X-EBRT, P-EBRT, and C-EBRT treatments. The data express a high degree of correlation between the predicted TCP outcomes and the reported bNED clinical outcomes, providing a measure of confidence in the accuracy of the TCP model across the various treatment modalities, risk groups, and fractionation schemes. The lack of a distinct pattern in the scatter of the residuals of the X-EBRT and PEBRT indicates a low likelihood of systematic error. However, the TCP model does tend to overestimate the effectiveness of C-EBRT; this is most likely due to both radiobiological and geometrical matters, which are discussed further later.

The performance of the model as judged against the validation datasets further strengthens the credibility of this TCP model. However, a limitation of the validation dataset is that only X-EBRT data were available as all the P-EBRT and C-EBRT data were included in the model fit. Further refinement and future validation of the model are required once pertinent clinical outcome data mature.

\section{B. Justification for the use of fixed parameter values}

The intrinsic radiosensitivity of prostate cancer is independent of risk group. ${ }^{58}$ The radiosensitivity values $\left(\bar{\alpha}=0.25 \mathrm{~Gy}^{-1}\right.$, $\bar{\alpha} / \bar{\beta}=2.48 \mathrm{~Gy}, \sigma_{\alpha}=11.3 \%, \sigma_{\beta}=12.9 \%$ ) used here were 


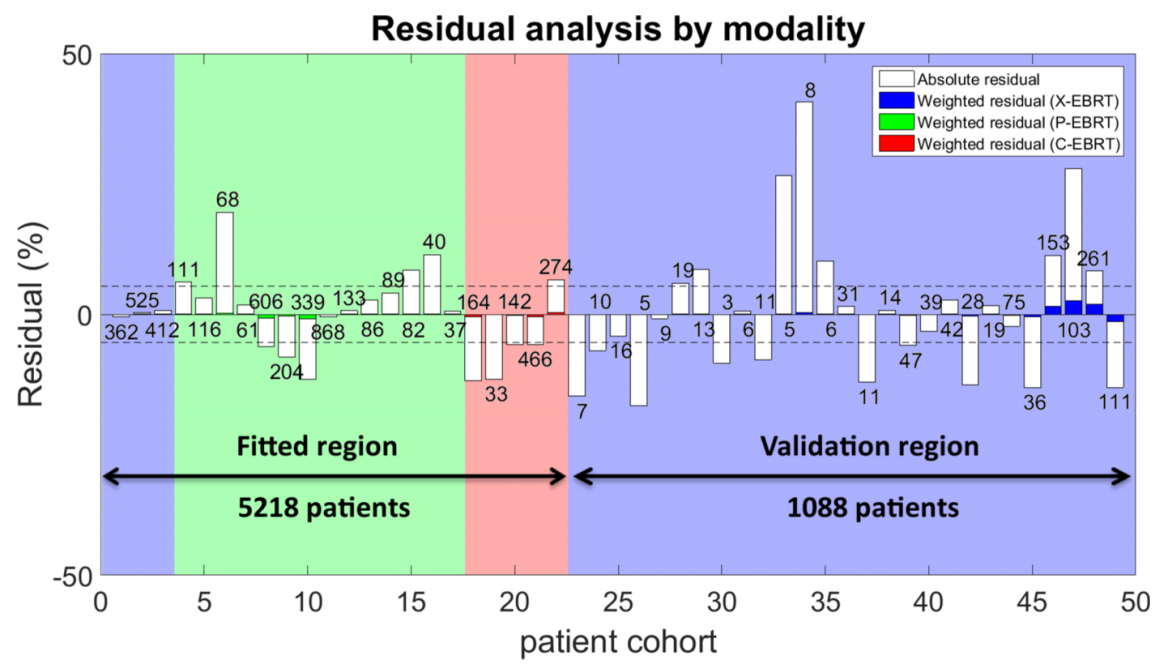

FIG. 2. Residuals for both the fitted and validation clinical outcome datasets: The right side of the fitted region corresponds to C-EBRT, the middle portion of the fitted region corresponds to P-EBRT, and the left side of the fitted region as well at the entire validation region corresponds to X-EBRT. The graph displays the residuals in terms of the absolute magnitude (white bars) and the weighted magnitude (colored bars for C-EBRT, P-EBRT, and X-EBRT, respectively). The area of the bars is filled with the appropriate color to signify the relative weight of that data point, e.g., a data point representing $50 \%$ of the fitted region would be $50 \%$ filled with color. The interpretation of this residual graph is best described as follows: Ideally, there would be no bars visible. If bars are visible they ought not to contain color, indicating a low weight. The worst case scenario is that a large bar is visible and that it is full of color, indicating a high weight. The weighted mean absolute residual across the entire dataset is found to be $\pm 5.4 \%$ and is depicted by two dashed horizontal lines. The fitted region consists of seven X-EBRT, P-EBRT, and C-EBRT datasets Refs. 23-28 comprising 22 data points containing a total of 5218 low, intermediate, and high-risk patients. The validation region consists of three X-EBRT datasets Refs. 55-57 comprising 27 data points containing a total of 1088 low, intermediate, and high-risk patients. The numbers above and below the bars indicate the number of patients associated with that data point.

obtained in a previous fit of this TCP model. ${ }^{22}$ These radiosensitivity values are in excellent agreement with both experimental and clinical values reported in the literature through meta-analysis. ${ }^{11,12}$ This approach ${ }^{47}$ enabled fitting of the DIL volume and the hypoxic fraction for low and high-risk prostate cancer patients, as well as $\mathrm{RBE}_{\min }$ and $\mathrm{RBE}_{\max }$ for P-EBRT and C-EBRT, in addition to the modification of the OER in the case of C-EBRT. The DIL volume and the hypoxic fraction for intermediate-risk prostate cancer patients were known from the previous fit of this TCP model ${ }^{22}$ for intermediate-risk patients treated by X-EBRT.

\section{C. The hypoxic fraction}

Hypoxia in prostate cancer is associated with reduced clinical tumor control. ${ }^{59,60}$ The estimated magnitude of the hypoxic fraction listed in Table II is similar to values used in the previous modeling studies. ${ }^{12,51}$ Experimental and clinical evidence also supports the validity of this result. A survey of all published data on hypoxic tumor fractions reported that hypoxic fractions ranged from $0 \%$ to $50 \%$, with a mean value of $15 \% .{ }^{53}$ This is similar to our mean hypoxic fraction of $14.6 \%$, averaged across all risk groups.

\section{D. The influence of the hypoxic fraction}

Hypoxia is a key factor, together with radiosensitivity, clonogen number, and dose, in determining TCP. Figure 4 shows the influence of hypoxia as a parameter on the relationship between $\mathrm{CTV} /$ clonogen number and the predicted TCP. A modest relationship is shown to exist between the CTV/clonogen number and TCP. Conversely, the figure evidently shows that the relationship between TCP and the hypoxic fraction governs.

\section{E. The oxygen enhancement ratio}

In this study, we assume (as have others ${ }^{51,61}$ ) that the OER value is consistent for both alpha and beta; however, other studies have assumed and reported that the OER varies. ${ }^{12,62}$ Furthermore, in this study, we also assume that the OER remains constant for all the fractionation regimes ${ }^{63}$ for the low LET treatment modalities, X-EBRT and P-EBRT. However, it is well known that for high LET radiation, the OER is reduced ${ }^{64}$ Typical dose mean LET values within the target during C-EBRT treatment of the prostate are $50-60 \mathrm{keV} / \mu \mathrm{m} .{ }^{39}$ Reduction of the OER effect through CEBRT LET was found to be $14.4 \%$. This is in good agreement with experimental in vitro results, where a reduction of $14 \%$ has been reported in the OER for this change in LET. ${ }^{41}$ These assumptions influence the model fit.

\section{F. Dominant intraprostatic lesions}

DILs are known to occur within the prostate and reoccurrence is typically located in these regions. ${ }^{12}$ The estimated magnitude of the DIL volumes listed in Table II (12.3\% averaged across all risk groups) is comparable to values which have been measured in clinical studies. ${ }^{37}$ Studies utilizing imaging techniques, such as dynamic contrast enhanced MRI and spectroscopic MRI, ${ }^{11} \mathrm{C}$-acetate and ${ }^{111} \mathrm{In}$-capromabpendetide, and ${ }^{18} \mathrm{~F}$-choline PET/CT, have reported the average DIL volume across all risk groups to be approximately $9 \%$ with a range of $1 \%-37 \% .33-38$ 
(A) OER:C-EBRT

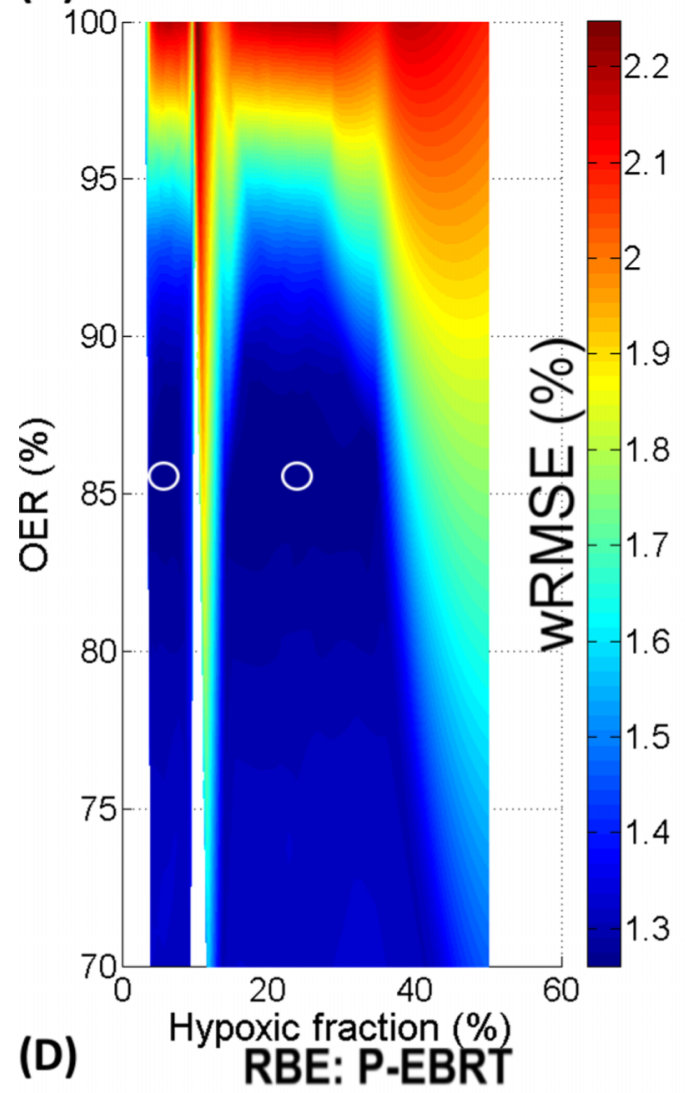

(B) High-risk patients

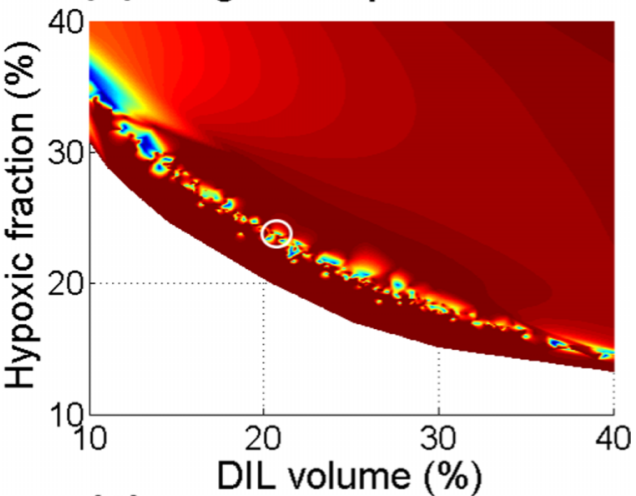

(C) Low-risk patients

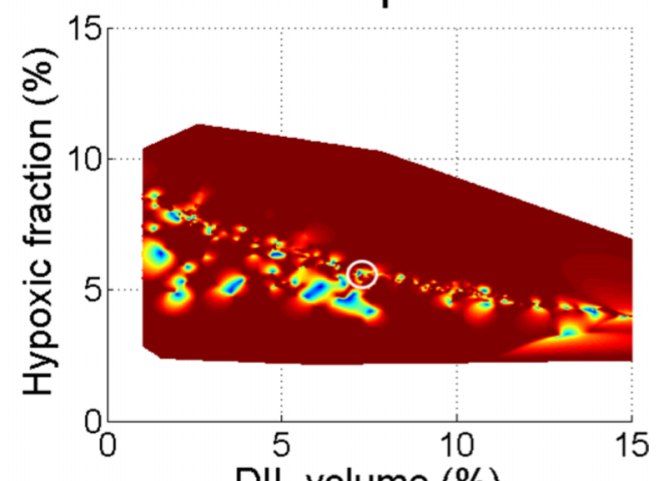

(E)

DIL volume (\%)

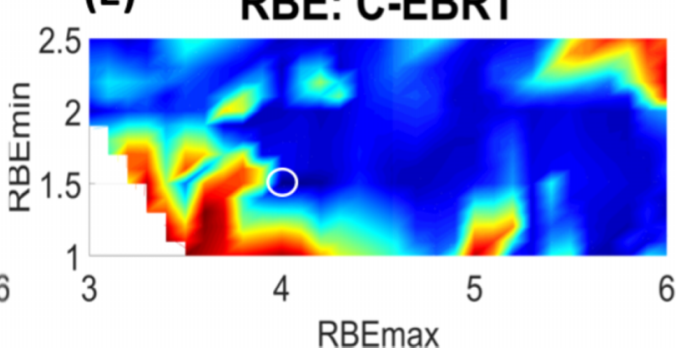

FIG. 3. Biological solution space: A surface plot of the biological solution space is shown here and can be interpreted as an uncertainty map. The optimal global minimum solution or the smallest wRMSE (depicted here as white circles) is found at DIL volumes equal to $7.4 \%$ and $20.9 \%$ with hypoxic fractions equal to $5.6 \%$ and $23.8 \%$ for the low and high-risk groups, respectively. The corresponding $\mathrm{RBE}_{\min }$ and $\mathrm{RBE}_{\max }$ values for both P-EBRT and C-EBRT are $1.0-1.2$ and 1.5-3.9, respectively. The OER reduction for C-EBRT is found to be optimal at 14.4\%. An inverse relationship between the hypoxic fraction and the DIL volume for low and high-risk patients is shown in (B) and (C). (A) displays the reduction in the OER for C-EBRT treatments for both low and high-risk patients (left and right circles, respectively). The discontinuity is indicative of the boundary between low and high-risk patients. The OER was optimized simultaneously in both risk groups, hence producing a single solution for both risk groups. (D) shows that the range of $\mathrm{RBE}_{\min }$ and $\mathrm{RBE}_{\max } \mathrm{Values}_{\text {for }} \mathrm{P}-\mathrm{EBRT}$ is bounded to approximately 1.0-1.2 while (E) shows a much greater range of $\mathrm{RBE}_{\min }$ and $\mathrm{RBE}_{\max }$ values for C-EBRT, permutations between 1.0-2.5 and 3.0-6.0 are depicted. This is due to the narrow 5-year bNED range of the C-EBRT dataset (81\%-100\%) in contrast to the 5-year bNED characteristics of the P-EBRT dataset $(48 \%-100 \%)$.

\section{G. The clinical significance of clongenic density, distribution, and number}

Accurate estimations of the density of clonogens in human tumors ${ }^{12}$ fall in the range of $10^{5}-10^{7} \mathrm{~cm}^{-3}$. Using these values for clonogen density in combination with the assumption that clonogens are homogeneously distributed throughout the CTV is a flawed approach and leads to an inflated estimate of the total initial clonogen number and of radiosensitivity. ${ }^{22}$ Advanced imaging techniques and histological analysis of radical prostatectomy specimens have demonstrated that clonogen density is not homogeneous. ${ }^{33-36,65}$ Frequently a single large DIL within the prostate is present. This has led to the development of dose painting approaches ${ }^{66-69}$ and consequently TCP models that require this feature. ${ }^{70,71}$ Other TCP models that do not account for this feature (whilst perfectly appropriate for the prediction of uniform doses) are intrinsically lacking in the context of dose and/or LET painting scenarios, ${ }^{72,73}$ which will likely become more prevalent in the future. It should be noted that the assumption of clongenic densities $\left(P_{\mathrm{CTV}}\right.$ and $\left.P_{\mathrm{DIL}}\right)$ influences the model fit and that the model fit cannot determine the distribution of clongenic densities. 


\section{The variation of TCP with CTV / clonogen number and hypoxic fraction}

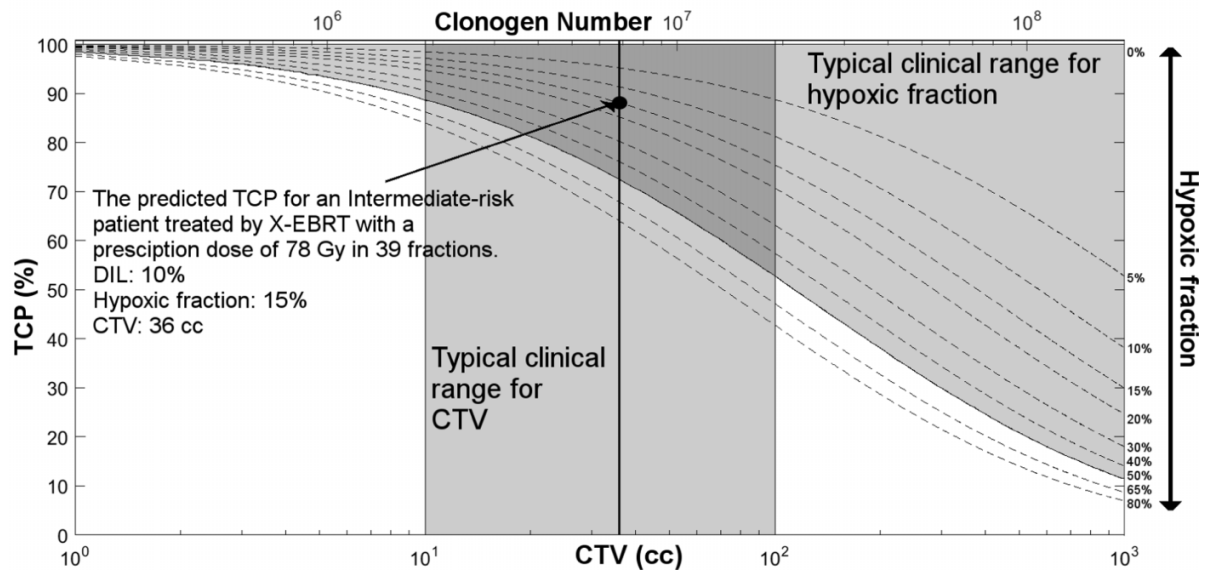

FIG. 4. Variation of TCP with CTV/clonogen number and hypoxic fraction: The variation of TCP with tumor volume and hypoxic fraction is shown. TCP was calculated for X-EBRT total dose of $78 \mathrm{~Gy}$ delivered in 39 fractions using the biological input parameters $\bar{\alpha}=0.25 \mathrm{~Gy}^{-1}, \bar{\alpha} / \bar{\beta}=2.48 \mathrm{~Gy}, \sigma_{\alpha}=11.3 \%$, $\sigma_{\beta}=12.9 \%$, DIL volume $=10 \%$, and OER $=1.75$. The light gray regions show the typical clinical range for CTV/clonogen number and hypoxic fraction. The dark gray region displays the overlap of these variables.

\section{H. Proliferation in prostate cancer}

Proliferation has been shown to be of importance in radiotherapy $;{ }^{74}$ nevertheless, it is not included in the TCP model as prostate cancer is typically a slowly proliferating cancer with a protracted delay before the commencement of regrowth. ${ }^{75,76}$ A recent analysis ${ }^{77}$ resulted in best estimates for proliferation values of delay of onset before rapid proliferation, $T(k)=34$ \pm 7 days, and proliferative doubling time, $T(d)=12 \pm 2$ days. These values have limited influence on standard fractionation and little or no effect on hypofractionation; however, in the setting of low dose rate brachytherapy, these values would have a major influence. The absence of proliferation is defensible for two reasons. First is that the model did not require a proliferation term to improve the fit of the model to the clinical outcome data. Second is the Akaike information criterion which evaluates the goodness of fit. ${ }^{78}$ This metric penalizes models with unnecessary parameters which do not contribute to the overall fit, therefore discouraging the inclusions of nonessential parameters.

\section{I. Application of the TCP model to other cancers}

This TCP model can be applied to other solid cancer types, provided that sufficient clinical outcome data are available to fit the model. Previously published values for radiosensitivity, clonogen density, and distribution coupled with hypoxia status enable comparison/benchmarking for the model fit values and strengthen the biological integrity of the model. Other clinical sites (e.g., lung and head and neck) may need to incorporate proliferation and the potential interplay effect with hypoxia, ${ }^{61}$ something which was not required for this prostate cancer study. However, it should be noted that there are implications for the Poissonian TCP approach implemented here in the context of very rapidly proliferating tumors. ${ }^{5}$ It has been demonstrated that the Poissonian TCP approach accurately describes the probability of tumor cure when no proliferation occurs during treatment; however, it underestimates cure when very rapid proliferation occurs, delay of onset before rapid proliferation, $T(k)=0$ days, and proliferative doubling time, $T(d)=2$ days. But even in this extreme context, the inaccuracy is not likely to exceed $10 \%$ and after most standard treatment regimens it would often be much less than that. ${ }^{5}$

\section{J. Hormonal therapy}

ADT does not affect radiosensitivity. ${ }^{58}$ The X-EBRT and C-EBRT datasets ${ }^{24,26-28}$ included ADT in all or a proportion of the treated patients. The use of ADT can potentially be a confounding factor and has been reported to improve bNED outcome by approximately $5 \%$ for all risk groups. However, it has also been reported that there is only a significant difference in the bNED rate for high-risk groups and is dependent on the period of ADT administration. ${ }^{79}$ Due to the lack of specific information with regard to ADT administration and conflicting reporting of efficacy in different risk groups, no explicit effort was made within this modeling study to correct for the impact from the use of ADT.

\section{K. Risk group stratification}

The exact definition of risk is controversial. Typical best practice for risk classification incorporates three stratification criteria: PSA level, Gleason histologic score, and tumor stage to identify low, intermediate, and high-risk tumors. Definitions to determine risk include any one of, or any dual combination (comb) of, PSA, Gleason score, or clinical staging. Furthermore, the values of PSA, Gleason score, or clinical stage used to stratify risk vary. The difference and overlap of definitions of patient risk, as depicted in Fig. 5, contribute to the overall uncertainty of modeling. There is a reasonable, but nonideal, degree of consistency within the dataset with respect to risk group stratification. Overlap between risk groups exists in all three stratification criteria. Improvements in the consistency of risk 


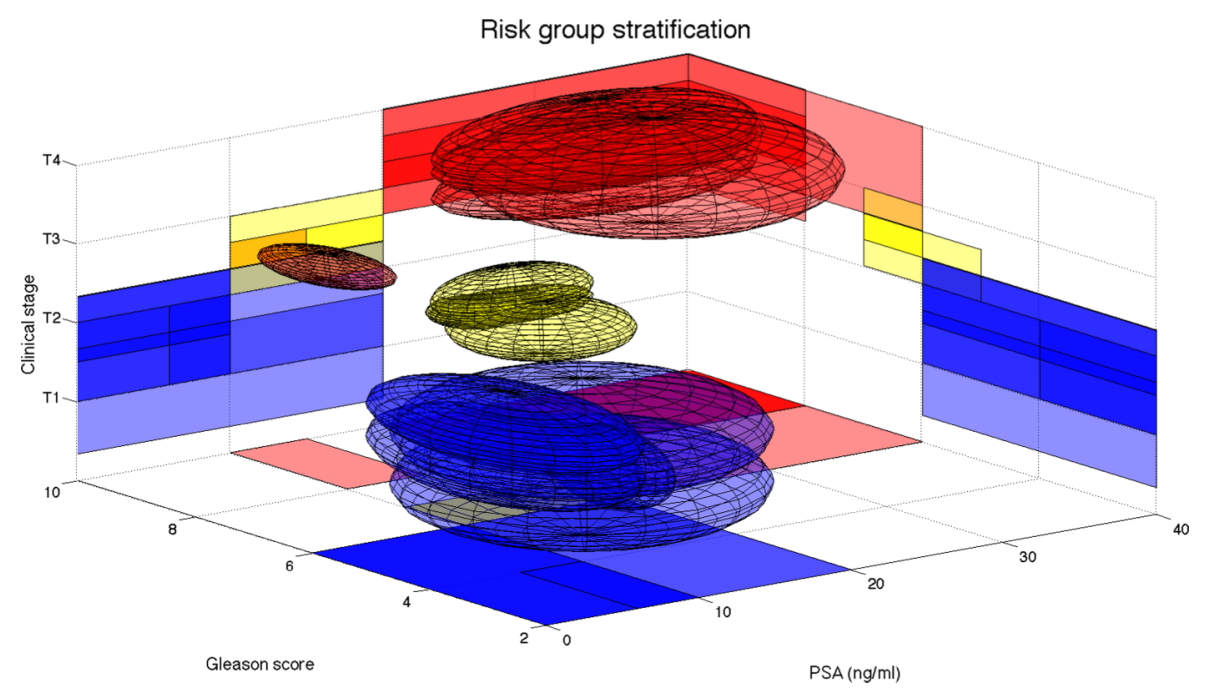

FIG. 5. Variation in risk group stratification: The image displays the disparity of exact definitions of risk. The ellipsoids represent patients classified in various studies (see Table I) as low, intermediate, and high-risk, respectively, using the three stratification criteria of PSA, Gleason score, and clinical staging. Color intensity reflects overlap. The lower cluster of ellipsoids correspond to low-risk stratification, the middle cluster of ellipsoids corresponds to intermediate-risk stratification, and the upper cluster of ellipsoids corresponds to high-risk stratification.

stratification reporting would increase the analytical utility of future data.

\section{L. The definition of clinical outcomes}

Evolution in clinical practice produces legacy issues for modeling. ${ }^{80,81}$ In this study, bNED is defined by either the American Society for Therapeutic Radiology and Oncology (ASTRO - three consecutive PSA rises post the PSA nadir) or the Phoenix Consensus Conference (PCC $-2 \mathrm{ng} / \mathrm{ml}$ PSA rise above the PSA nadir) definition of biochemical failure. ${ }^{82}$ Control rates defined by the ASTRO definition appear to be worse at 2-5 yr, are convergent at 5-8 yr, and superior at $8-12 \mathrm{yr}$ in comparison with the PCC definition. The sensitivity and specificity of the PCC definition is considered to be more robust. ${ }^{82}$ This difference contributes to the overall uncertainty of modeling. A primary endpoint of 5-year bNED is utilized in this study. While utilization of both definitions is nonideal, it can be justified for the following two reasons: (1) A two-sample Kolmogorov-Smirnov test revealed that the residuals from each definition are from the same continuous distribution, i.e., the model does not significantly over or underestimates bNED for either definition. (2) Strict adherence to the current PCC definition would result in exclusion of half the data listed in Table I (most notably in the P-EBRT dataset, $\sim 92 \%$ is defined according to the ASTRO definition).

\section{M. Dose heterogeneity}

Dose heterogeneity can affect the results of TCP modeling, ${ }^{83,84}$ with underdosed areas being of special concern. ${ }^{32}$ $\mathrm{X}$-EBRT of the prostate with conformal radiotherapy is acknowledged as a robust treatment technique, ${ }^{85}$ delivering a highly uniform dose to the target, ${ }^{86}$ consequently reducing the possible influence of dose heterogeneity and cold spots upon the TCP model. Subset analysis of X-EBRT resulted in excellent correlation. Subset analysis of P-EBRT and C-EBRT resulted in worse correlation, particularly in C-EBRT. The well-defined range of ions enables precise dose localization and highly conformal treatments. However, this property renders ions sensitive to targeting uncertainties, ${ }^{87}$ relevant for the prostate which undergoes considerable interfraction displacements. ${ }^{88}$ Typical planning for C-EBRT completely removes the posterior margin from the PTV in the latter half of treatment. ${ }^{24,26,28}$ This possibly leads to cold spots in the clinical target volume during C-EBRT treatment. The delivered dose and prescribed dose may, therefore, be different; this could potentially explain the systematic overestimation of the TCP model in predicting clinical outcome for C-EBRT.

\section{N. Relative biological effectiveness}

Clinical RBE values of 1.1 and 3.0 are used for P-EBRT and C-EBRT, respectively. ${ }^{43}$ The studies included in our meta-analysis followed this convention. However, the RBE of ions varies with LET, dose, and radiosensitivity. ${ }^{44}$ The RBE of P-EBRT and C-EBRT has been reported to vary between $1.0-1.4$ and 1.5-6.7, respectively. ${ }^{89}$ The estimated values from this TCP model of $\mathrm{RBE}_{\min }$ and $\mathrm{RBE}_{\max }$ for $\mathrm{P}$ EBRT and C-EBRT listed in Table II are in agreement with these previous findings. This variation in RBE potentially has important ramifications for both dose/LET painting and extreme fractionation regimens.

\section{O. The limitations of the TCP model}

The TCP model was fitted and validated to a primary endpoint of 5-year bNED clinical outcome data. This has two important consequences: the first is that the model is constrained to a particular time point and the second is that the model predicts population outcomes. In principle, the model could predict both population outcomes and individual outcomes, such as the Kattan-nomogram; ${ }^{90}$ however, precise knowledge at the voxel level of each individual's 
intratumor radiosensitivity, clonogenic density and clonogenic distribution, hypoxia status, and RBE would be required to be accurate. In order to overcome the temporal limitations of this model, other mathematical approaches are required such as the Zaider-survival-model. ${ }^{9}$ Finally, with regard to the mathematical nature of the TCP model, it has been demonstrated that the Poissonian TCP approach in the context of very rapidly proliferating tumors ${ }^{5}$ has the potential to underestimate cure (in this scenario the model would require the incorporation of a repopulation term ${ }^{74}$ ). However, there is also an additional associated concern that when fitting a Poisson model to clinical outcome data from a homogeneous population of rapidly proliferating tumors, the estimate of total initial clonogen number $N_{0}$ is biased downward (while the resulting estimates of radiosensitivity and/or tumor growth rate should still accurately reflect true values). ${ }^{5}$ In this study, these concerns are offset by the fact that prostate cancer is a heterogeneous population ${ }^{91}$ (accounted for in this mechanistic TCP model through distribution of the radiosensitivity values) of nonrapidly proliferating tumors ${ }^{75,76}$ (negating the need for a repopulation term).

\section{P. The TCP model qualitatively compared with other empirical models}

Preceding work has presented TCP models fitted to clinical outcome data, such as those previously fitted to the validation dataset ${ }^{55-57}$ utilized here. While they are appropriate for the reproduction of the curve from which they were derived, problems arise when extrapolating to situations that have some changes compared to the reference conditions, i.e., fractionation schemes. Empirical models such as the standard Poisson, logistic, and Probit models, while useful for prediction in a single fractionation domain space, offer limited insight into the multiparametric complex causal physical and biological processes present in EBRT treatment. Parametric information with regard to intertumor radiosensitivity, clonogenic density and clonogenic distribution, hypoxia status, and RBE is all crudely encapsulated by $D 50$ and $\gamma$ values (i.e., these quantities change when risk group, treatment modality, or fractionation regimes change and are only applicable to uniform dose distributions). Mechanistic models are intrinsically more powerful than empirical models as they parametrically represent the fundamental processes driving patterns and are more likely to work correctly when extrapolating beyond the observed conditions, as was demonstrated with this TCP model which extrapolated accurately to the stereotactic body radiotherapy fractionation domain space. ${ }^{22}$ This is in stark contrast to the empirical models previously fitted to the validation dataset, ${ }^{55-57}$ which are constrained to conditions of the fit (low, intermediate, and high-risk patients, treated by X-EBRT with fractionation of 1.8-2.0 Gy). The TCP model presented here has been fitted and validated in the context of low, intermediate, and high-risk patients, treated by X-EBRT, P-EBRT, and C-EBRT with fractionation of 1.8-3.6 Gy. These are important facts with respect to this TCP model which distinguishes it from other models.

\section{Q. The merit of mechanistic models}

A triumph of radiobiological research in radiation oncology is the prediction of dose response. In contrast to empirical models, mechanistic models accomplish this task with two distinct advantages: ${ }^{6}(1)$ mechanistic models are much less prone to overfitting and (2) their parameters characteristically permit biophysical explanation, therefore maximizing the value of such models as tools of scientific discovery. This is the case with this TCP model as estimates of intertumor radiosensitivity, clonogenic density and clonogenic distribution, hypoxia status, and RBE are all provided. Nevertheless, the TCP model presented here is also out of necessity a simplification of the enormously complex reality of the dynamics of irradiated tumors. Many other factors that influence the response of tumors to irradiation such as the delivered dose distribution, birth-and-death stochastic processes, cell cycling, interaction with the immune system, selection effects, spatial heterogeneity of the tumor, and its capillary network, were not taken into account. These factors will have all played a role to one degree or another in determining outcomes and remain a challenge for the scientific community to address and quantify through modeling.

\section{CONCLUSION}

A TCP model for prostate cancer has been demonstrated to accurately forecast the 5-year bNED clinical outcomes in both the fit and validation datasets, irrespective of treatment modality, risk group, or fractionation scheme, using optimized biological and radiosensitivity values. The values obtained for the biological input parameters of the TCP model are in good agreement with the previously reported values within the literature. These biological values were obtained through a fitting procedure, based upon clinical outcome data of 5218 prostate cancer patients. The results suggest that the model presented is appropriate for the analysis and evaluation of EBRT plans with regard to tumor control for a wide variety of treatment techniques and clinical conditions. Finally, highlevel randomized evidence is yet to be provided for both PEBRT and C-EBRT. The mathematical construct of this TCP model enables it to assist in future clinical trial design and sample size determination.

\section{ACKNOWLEDGMENT}

This work was supported by the ENVISION project, which is cofunded by the European Commission under FP7 Grant Agreement No. 241851. The financial support by the Austrian Federal Ministry of Science, Research and Economy and the National Foundation for Research, Technology and Development is gratefully acknowledged.

\section{APPENDIX: SUPPLEMENTAL TABLES}

The purpose of this appendix is to provide two tables which summarize the TCP model parameters and the validation dataset. Data is available at doi:10.17195/candat.2015.10.8. 
TABLE III. Summary of the TCP model parameters.

\begin{tabular}{lllc}
\hline \hline Parameter & \multicolumn{1}{c}{ Association } & \multicolumn{1}{c}{ Estimated from } & Input value \\
\hline$\alpha$ & Cancer type (prostate) & Previous fit & $0.25 \mathrm{~Gy}^{-1}$ \\
$\beta$ & Cancer type (prostate) & Previous fit & $0.10 \mathrm{~Gy}^{-2}$ \\
$\sigma_{\alpha}$ & Cancer type (prostate) & Previous fit & $11.30 \%^{\mathrm{a}}$ \\
$\sigma_{\beta}$ & Cancer type (prostate) & Previous fit & $12.90 \%^{\mathrm{a}}$ \\
$\mathrm{RBE}_{\max }$ & Modality (P-EBRT) & Current fit & 1.20 \\
& Modality (C-EBRT) & Current fit & 3.90 \\
$\mathrm{RBE}_{\min }$ & Modality (P-EBRT) & Current fit & 1.00 \\
& Modality (C-EBRT) & Current fit & 1.50 \\
OER & Modality (X-EBRT/P-EBRT) & Previous/current assumption & 1.75 \\
& Modality (C-EBRT) & Current fit & 1.50 \\
$\mathrm{CTV}$ & Risk (low/intermediate) & Current/previous assumption & $36.00 \mathrm{~cm}^{3}$ \\
& Risk (high) & Current assumption & $72.00 \mathrm{~cm}^{3}$ \\
DIL & Risk (low) & Current fit & $7.40 \%^{\mathrm{b}}$ \\
& Risk (intermediate) & Previous assumption & $10.00 \%^{\mathrm{b}}$ \\
& Risk (high) & Current fit & $20.90 \%^{\mathrm{b}}$ \\
Hypoxic fraction & Risk (low) & Current fit & $5.60 \%^{\mathrm{b}}$ \\
& Risk (intermediate) & Previous assumption & $15.00 \%^{\mathrm{b}}$ \\
& Risk (high) & Current fit & $23.80 \%^{\mathrm{b}}$ \\
\hline \hline
\end{tabular}

${ }^{\text {a }}$ The value is a percentage of the appropriate radiosensitivity characteristic $\alpha$ or $\beta$.

${ }^{\mathrm{b}}$ The value is a percentage of the appropriate CTV value low/intermediate or high.

TABLE IV. Clinical outcome dataset for validating the TCP model.

\begin{tabular}{|c|c|c|c|c|c|c|c|}
\hline Pats No. & Modality & $d(\mathrm{~Gy})$ & $D(\mathrm{~Gy})$ & 5-year bNED (\%) & ADT & Risk & References \\
\hline 7 & X-EBRT & 1.8 & 68.4 & 55 (ASTRO) & No & Low-comb & Levegrün et al. (Ref. 57) \\
\hline 10 & X-EBRT & 1.8 & 72.8 & 77 (ASTRO) & No & Low-comb & Levegrün et al. (Ref. 57) \\
\hline 16 & X-EBRT & 1.8 & 78.4 & 89 (ASTRO) & No & Low-comb & Levegrün et al. (Ref. 57) \\
\hline 5 & X-EBRT & 1.8 & 66.6 & 20 (ASTRO) & No & Int-comb & Levegrün et al. (Ref. 57) \\
\hline 9 & X-EBRT & 1.8 & 72.0 & 62 (ASTRO) & No & Int-comb & Levegrün et al. (Ref. 57) \\
\hline 19 & X-EBRT & 1.8 & 77.4 & 20 (ASTRO) & No & Int-comb & Levegrün et al. (Ref. 57) \\
\hline 13 & X-EBRT & 1.8 & 82.8 & 100 (ASTRO) & No & Int-comb & Levegrün et al. (Ref. 57) \\
\hline 3 & X-EBRT & 1.8 & 66.6 & 0 (ASTRO) & No & High-comb & Levegrün et al. (Ref. 57) \\
\hline 6 & X-EBRT & 1.8 & 72.0 & 29 (ASTRO) & No & High-comb & Levegrün et al. (Ref. 57) \\
\hline 11 & X-EBRT & 1.8 & 77.4 & 44 (ASTRO) & No & High-comb & Levegrün et al. (Ref. 57) \\
\hline 5 & X-EBRT & 1.8 & 82.8 & 100 (ASTRO) & No & High-comb & Levegrün et al. (Ref. 57) \\
\hline 8 & X-EBRT & 2.0 & 60.0 & 82 (ASTRO) & No & Low-comb & Cheung et al. (Ref. 56) \\
\hline 6 & X-EBRT & 2.0 & 62.0 & 62 (ASTRO) & No & Low-comb & Cheung et al. (Ref. 56) \\
\hline 31 & X-EBRT & 2.0 & 64.0 & 63 (ASTRO) & No & Low-comb & Cheung et al. (Ref. 56) \\
\hline 11 & X-EBRT & 2.0 & 66.0 & 57 (ASTRO) & No & Low-comb & Cheung et al. (Ref. 56) \\
\hline 14 & X-EBRT & 2.0 & 68.0 & 78 (ASTRO) & No & Low-comb & Cheung et al. (Ref. 56) \\
\hline 47 & X-EBRT & 2.0 & 70.0 & 77 (ASTRO) & No & Low-comb & Cheung et al. (Ref. 56) \\
\hline 39 & X-EBRT & 2.0 & 78.0 & 92 (ASTRO) & No & Low-comb & Cheung et al. (Ref. 56) \\
\hline 42 & X-EBRT & 2.0 & 64.0 & 38 (ASTRO) & No & Int-comb & Cheung et al. (Ref. 56) \\
\hline 28 & X-EBRT & 2.0 & 66.0 & 32 (ASTRO) & No & Int-comb & Cheung et al. (Ref. 56) \\
\hline 19 & X-EBRT & 2.0 & 68.0 & 57 (ASTRO) & No & Int-comb & Cheung et al. (Ref. 56) \\
\hline 75 & X-EBRT & 2.0 & 70.0 & $62(\mathrm{ASTRO})$ & No & Int-comb & Cheung et al. (Ref. 56) \\
\hline 36 & X-EBRT & 2.0 & 78.0 & 74 (ASTRO) & No & Int-comb & Cheung et al. (Ref. 56) \\
\hline 153 & X-EBRT & 2.0 & 66.0 & 25 (ASTRO) & No & High-comb & Cheung et al. (Ref. 55) \\
\hline 103 & X-EBRT & 2.0 & 68.0 & 49 (ASTRO) & No & High-comb & Cheung et al. (Ref. 55) \\
\hline 261 & X-EBRT & 2.0 & 70.0 & 38 (ASTRO) & No & High-comb & Cheung et al. (Ref. 55) \\
\hline 111 & X-EBRT & 2.0 & 78.0 & 52 (ASTRO) & No & High-comb & Cheung et al. (Ref. 55) \\
\hline
\end{tabular}

Note: Comb is defined as satisfying any dual combination of PSA, Gleason score, or clinical staging to determine risk. bNED is defined as the American Society for Therapeutic Radiology and Oncology (ASTRO-three consecutive PSA rises post the PSA nadir). 
a)Author to whom correspondence should be addressed. Electronic mail walshsharp@gmail.com

${ }^{1}$ WHO, Estimated age-standardised incidence and mortality rates: Men, 2012.

${ }^{2}$ L. Gerber, L. Banez, and S. Freedland, "Defining and treating high-risk prostate cancer: Can we do better?," Eur. Urol. 58, 8-11 (2010).

${ }^{3}$ P. Gastelblum, M. Roelandts, and P. van Houtte, "External radiotherapy and prostate cancer," Eur. Urol., Suppl. 5, 487-490 (2006).

${ }^{4} \mathrm{~J}$. Wang, M. Guerrero, and X. Li, "How low is the alpha/beta ratio for prostate cancer?,” Int. J. Radiat. Oncol., Biol., Phys. 55, 194-203 (2003).

${ }^{5} \mathrm{~S}$. Tucker, H. Thames, and J. Taylor, "How well is the probability of tumor cure after fractionated irradiation described by Poisson statistics?," Radiat. Res. 124, 273-282 (1990).

${ }^{6}$ M. Zaider and L. Hanin, "Tumor control probability in radiation treatment," Med. Phys. 38, 574-583 (2011).

${ }^{7} \mathrm{M}$. Zaider and G. Minerbo, "Tumour control probability a formulation applicable to any temporal protocol of dose delivery," Phys. Med. Biol. 45, 279-293 (2000).

${ }^{8}$ M. Zaider, M. Zelefsky, G. Cohen, C. Chui, E. Yorke, L. Ben-porat, and L. Happersett, "Methodology for biologically-based treatment planning for combined low-dose-rate (permanent implant) and high-dose-rate (fractionated) treatment of prostate cancer," Int. J. Radiat. Oncol., Biol., Phys. 61, 702-713 (2005).

${ }^{9}$ M. Zaider, M. Zelefsky, L. Hanin, A. Tsodikov, A. Yakovlev, and S. Leibel, "A survival model for fractionated radiotherapy with an application to prostate cancer," Phys. Med. Biol. 46, 2745-2758 (2001).

${ }^{10}$ R. Valdagnia, C. Italia, P. Montanaro, A. Lanceni, P. Lattuada, T. Magnani, C. Fiorino, and A. Nahum, "Is the alpha/beta ratio of prostate cancer really low? A prospective, non-randomized trial comparing standard and hyperfractionated conformal radiation therapy," Radiother. Oncol. 75, 74-82 (2005).

${ }^{11} \mathrm{~S}$. Oliveira, N. Teixeira, and L. Fernades, "What do we know about the alpha/beta for prostate cancer?," Med. Phys. 39, 3189-3201 (2012).

${ }^{12}$ A. Nahum, B. Movas, E. Horwitz, C. Stobbes, and J. Chapman, "Incorporating clinical measurements of hypoxia into tumor local control modeling of prostate cancer: Implications for the alpha/beta ratio," Int. J. Radiat. Oncol., Biol., Phys. 57, 391-401 (2003).

${ }^{13} \mathrm{H}$. Kal and M. V. Gellekom, "How low is the alpha/beta ratio for prostate cancer?,” Int. J. Radiat. Oncol., Biol., Phys. 57, 1116-1121 (2003).

${ }^{14}$ J. Fowler, R. Chappell, and M. Ritter, "Is alpha/beta for prostate tumors really low?," Int. J. Radiat. Oncol., Biol., Phys. 50, 1021-1031 (2001).

${ }^{15} \mathrm{D}$. Brenner and E. Hall, "Fractionation and protraction for radiotherapy of prostate carcinoma," Int. J. Radiat. Oncol., Biol., Phys. 43, 1095-1101 (1999).

${ }^{16}$ T. Kanai, N. Matsufuji, T. Miyamoto, J. Mizoe, T. Kamada, H. Tsuji, H. Kato, M. Baba, and H. Tsujii, "Examination of GyE system for HIMAC carbon therapy," Int. J. Radiat. Oncol., Biol., Phys. 62, 650-656 (2006).

${ }^{17} \mathrm{~S}$. Webb and A. Nahum, "A model for calculating tumour control probability in radiotherapy including the effects of inhomogeneous distributions of dose and clonogenic cell density," Phys. Med. Biol. 38, 653-666 (1993).

${ }^{18}$ T. Miyamoto, N. Yamamoto, H. Nishimura, M. Koto, H. Tsujii, J. Mizoe, T. Kamada, H. Kato, S. Yamada, S. Morita, K. Yoshikawa, S. Kandatsu, and T. Fujisaw, "Carbon ion radiotherapy for stage I non-small cell lung cancer," Radiother. Oncol. 66, 127-140 (2003).

${ }^{19}$ K. Hayakawa, N. Mitsuhashi, Y. Saito, Y. Nakayama, S. Katano, M. Furuta, H. Sakurai, T. Takahashi, and H. Niibe, "Definitive radiation therapy for medically inoperable patients with stage I and II non-small cell lung cancer," Radiat. Oncol. Invest. 4, 165-170 (1996).

${ }^{20} \mathrm{~N}$. Choi and J. Doucette, "Improved survival of patients with unresectable non-small-cell bronchogenic carcinoma by an innovated high-dose en-bloc radiotherapeutic approach," Cancer 48, 101-109 (1981).

${ }^{21} \mathrm{~L}$. Hanin and M. Zaider, "On the probability of cure for heavy-ion radiotherapy," Phys. Med. Biol. 59, 3829-3842 (2014).

${ }^{22}$ S. Walsh and W. van der Putten, "A TCP model for external beam treatment of intermediate-risk prostate cancer," Med. Phys. 40, 031709 (11pp.) (2013).

${ }^{23}$ N. Mendenhall, B. Hoppe, R. Nichols, W. Mendenhall, C. Morris, Z. Li, Z. $\mathrm{Su}, \mathrm{C}$. Williams, J. Costa, and R. Henderson, "Five-year outcomes from 3 prospective trials of image-guided proton therapy for prostate cancer," Int. J. Radiat. Oncol., Biol., Phys. 88, 596-602 (2014).

${ }^{24}$ H. Tsuji, T. Yanagi, H. Ishikawa, T. Kamada, J. Mizoe, T. Kanai, S. Morita, and H. Tsujii, "Hypofractionated radiotherapy with carbon ion beams for prostate cancer,” Int. J. Radiat. Oncol., Biol., Phys. 63, 1153-1160 (2005).

${ }^{25}$ J. Slater, C. Rossi, L. Yonemoto, D. Bush, B. Jabola, R. Levy, R. Grove, W. Preston, and J. Slater, "Proton therapy for prostate cancer: The initial Loma Linda University experience," Int. J. Radiat. Oncol., Biol., Phys. 59, 348-352 (2004)

${ }^{26}$ T. Okada, H. Tsuji, T. Kamada, K. Akakura, H. Suzuki, J. Shimazaki, and H. Tsujii, "Carbon ion radiotherapy in advanced hypofractionated regimens for prostate cancer: From 20 to 16 fractions," Int. J. Radiat. Oncol., Biol., Phys. 84, 968-972 (2012).

${ }^{27}$ M. Kollmeier, M. Katz, K. Mak, Y. Yamada, D. Feder, Z. Zhang, X. Jia, W. Shi, and M. Zelefsky, "Improved biochemical outcomes with statin use in patients with high-risk localized prostate cancer treated with radiotherapy," Int. J. Radiat. Oncol., Biol., Phys. 79, 713-718 (2011).

${ }^{28}$ H. Ishikawa, H. Tsuji, T. Kamada, T. Yanagi, J. Mizoe, T. Kanai, S. Morita, M. Wakatsuki, J. Shimazaki, and H. Tsujii, "Carbon ion radiation therapy for prostate cancer: Results of a prospective phase II study," Radiother. Oncol. 81, 57-64 (2006).

${ }^{29}$ A. Zietman, M. DeSilvio, J. Slater, C. Rossi, D. Miller, J. Adams, and W. Shipley, "Comparison of conventional-dose vs high-dose conformal radiation therapy in clinically localized adenocarcinoma of the prostate a randomized controlled trial (corrected)," JAMA 299, 899-900 (2008).

${ }^{30}$ T. Munro and C. Gilbert, "The relation between tumour lethal doses and the radiosensitivity of tumour cells,” Br. J. Radiol. 34, 246-251 (1961).

${ }^{31}$ D. Brenner, L. Hlatky, P. Hannfeldt, E. Hall, and R. Sachs, "A convenient extension of the LQ model to include redistribution and reoxygenation," Int. J. Radiat. Oncol., Biol., Phys. 32, 379-390 (1995).

${ }^{32} \mathrm{~S}$. Webb, P. Evans, W. Swindellt, and J. Deasy, "A proof that uniform dose gives the greatest TCP for fixed integral dose in the planning target volume," Phys. Med. Biol. 39, 2091-2098 (1994).

${ }^{33}$ B. Pickett, E. Vigneault, J. Kurhanewicz, and L. V. M. Roach, "Static field intensity modulation to treat a dominant intra-prostatic lesion to $90 \mathrm{~Gy}$ compared to seven field 3-dimensional radiotherapy," Int. J. Radiat. Oncol., Biol., Phys. 44, 921-929 (1999).

${ }^{34}$ J. Seppälä, M. Seppänen, E. Arponen, P. Lindholm, and H. Minn, "Carbon11 acetate PET/CT based dose escalated IMRT in prostate cancer," Radiother. Oncol. 93, 234-240 (2009).

${ }^{35}$ L. van den Bergh, M. Koole, S. Isebaert, S. Joniau, C. Deroose, R. Oyen, E. Lerut, T. Budiharto, F. Mottaghy, G. Bormans, H. van Poppel, and K. Haustermans, "Is there an additional value of ${ }^{11} \mathrm{C}$-choline PET-CT to T2weighted MRI images in the localization of intraprostatic tumor nodules?," Int. J. Radiat. Oncol., Biol., Phys. 83, 1486-1492 (2012).

${ }^{36}$ E. van Lin, J. Futterer, S. Heijmink, L. van der Vight, A. Hoffmann, P. van Kollenburg, H. Huisman, T. Scheenen, J. Witjes, J. Leer, J. Barentsz, and A. Visser, "IMRT boost dose planning on dominant intraprostatic lesions: Gold marker-based three-dimensional fusion of CT with dynamic contrastenhanced and ${ }^{1} \mathrm{H}$-spectroscopic MRI," Int. J. Radiat. Oncol., Biol., Phys. 65, 291-303 (2006).

${ }^{37}$ J. Pouliot, Y. Kim, E. Lessard, I. Hsu, D. Vigneron, and D. Kurhanewicz, "Inverse planning for HDR prostate brachytherapy used to boost dominant intraprostatic lesions defined by magnetic resonance spectroscopy imaging," Int. J. Radiat. Oncol., Biol., Phys. 59, 1196-1207 (2004).

${ }^{38}$ W. Wong, S. Schild, S. Vora, G. Ezzell, B. Nguyen, P. Ram, and M. Roarke, "Image-guided radiotherapy for prostate cancer: A prospective trial of concomitant boost using indium-111-capromab pendetide (prostascint) imaging," Int. J. Radiat. Oncol., Biol., Phys. 81, 423-429 (2011).

${ }^{39}$ E. Roelofs, L. Persoon, S. Qamhiyeh, F. Verhaegen, D. De Ruysscher, M. Scholz, G. Iancu, M. Engelsman, C. Rasch, L. Zijp, G. De Meerleer, M. Coghe, J. Langendijk, C. Schilstra, M. Pijls-Johannesma, and P. Lambin, "Design of and technical challenges involved in a framework for multicentric radiotherapy treatment planning studies," Radiother. Oncol. 97, 567-571 (2010).

${ }^{40}$ L. Gray, A. Conger, M. Ebert, S. Hornsey, and O. Scott, "The concentration of oxygen dissolved in tissues at the time of irradiation as a factor in radiotherapy," Br. J. Radiol. 26, 638-648 (1953).

${ }^{41} \mathrm{G}$. Barendsen, "Responses of cultured cells tumours and normal tissues to radiations of different linear energy transfer," Curr. Top. Radiat. Res. 4, 293-356 (1968).

${ }^{42}$ B. Jones and R. Dale, "Estimation of optimum dose per fraction for high let radiations: Implications for proton radiotherapy,” Int. J. Radiat. Oncol., Biol., Phys. 48, 1549-1557 (2000).

${ }^{43}$ H. Suit, T. DeLaney, S. Goldberg, H. Paganetti, B. Clasie, L. Gerweck, A. Niemierko, E. Hall, J. Flanz, J. Hallman, and A. Trofimov, "Proton vs carbon 
ion beams in the definitive radiation treatment of cancer patients," Radiother Oncol. 95, 3-22 (2010).

${ }^{44}$ A. Carabe-Fernandez, M. Moteabbed, N. Depauw, J. Schuemann, and H. Paganetti, "Range uncertainty in proton therapy due to variable biological effectiveness," Phys. Med. Biol. 57, 1159-1172 (2012).

${ }^{45}$ A. Carabe-Fernandez, R. Dale, and B. Jones, "The incorporation of the concept of minimum RBE (RBEmin) into the linear-quadratic model and the potential for improved radiobiological analysis of high-LET treatments,' Int. J. Radiat. Biol. 83, 27-39 (2007).

${ }^{46}$ R. Dale, B. Jones, and A. Carabe-Fernandez, "Why more needs to be known about RBE effects in modern radiotherapy," Appl. Radiat. Isot. 67, 387-392 (2009).

${ }^{47}$ R. Stewart and X. Li, "BGRT: Biologically guided radiation therapy-The future is fast approaching!," Med. Phys. 34, 3739-3751 (2007).

${ }^{48}$ J. Lagarias, J. Reeds, M. Wright, and P. Wright, "Convergence properties of the Nelder-Mead simplex method in low dimensions," SIAM J. Optim. 9, 112-147 (1998).

${ }^{49}$ K. Lee, D. Barber, and L. Walton, "Automated gamma knife radiosurgery treatment planning with image registration, data-mining, and Nelder-Mead simplex optimization," Med. Phys. 33, 2532-2540 (2006).

${ }^{50}$ J. Olofsson, T. Nyholm, A. Ahnesjo, and M. Karlsson, "Optimization of photon beam flatness for radiation therapy,” Phys. Med. Biol. 52, 1735-1746 (2007).

${ }^{51}$ J. Wang, X. Li, and N. Mayr, "Dose escalation to combat hypoxia in prostate cancer: A radiobiological study on clinical data,” Br. J. Radiol. 79, 905-911 (2006).

${ }^{52}$ M. Pinkawa, C. Attieh, M. D. Piroth, R. Holy, S. Nussen, J. Klotz, R. Hawickhorst, W. Schäfer, and M. Eble, "Dose-escalation using intensitymodulated radiotherapy for prostate cancer-Evaluation of the dose distribution with and without ${ }^{18} \mathrm{~F}$-choline PET-CT detected simultaneous integrated boost," Radiother. Oncol. 93, 213-219 (2009).

${ }^{53}$ J. Moulder and S. Rockwell, "Hypoxia fractions of solid tumors: Experimental techniques, methods of analysis and a survey of existing data," Int. J. Radiat. Oncol., Biol., Phys. 10, 695-712 (1984).

${ }^{54}$ G. De Meerleer, G. Villeirs, S. Bral, L. Paelinck, W. De Gersem, P. Dekuyper, and W. De Nevea, "The magnetic resonance detected intraprostatic lesion in prostate cancer: Planning and delivery of intensity-modulated radiotherapy," Radiother. Oncol. 75, 325-333 (2005).

${ }^{55}$ R. Cheung, S. Tucker, L. Dong, and D. Kuban, "Dose response for biochemical control among high-risk prostate cancer patients after external beam radiotherapy," Int. J. Radiat. Oncol., Biol., Phys. 56, 1234-1240 (2003).

${ }^{56}$ R. Cheung, S. Tucker, A. Lee, R. De Crevoisier, L. Dong, A. Kamat, L. Pisters, and D. Kuban, "Dose response characteristics of low- and intermediaterisk prostate cancer treated with external beam radiotherapy," Int. J. Radiat Oncol., Biol., Phys. 61, 993-1002 (2005).

${ }^{57}$ S. Levegrün, A. Jackson, M. Zelefsky, E. Venkatraman, M. Skwarchuk, W. Schlegel, Z. Fuks, S. Leibel, and C. Ling, "Risk group dependence of dose response for biopsy outcome after three dimensional conformal radiation therapy of prostate cancer," Radiother. Oncol. 63, 11-26 (2002).

${ }^{58}$ R. Miralbell, S. Roberts, E. Zubizarreta, and J. Hendry, "Dose-fractionation sensitivity of prostate cancer deduced from radiotherapy outcomes of 5,969 patients in seven international institutional datasets: $\alpha / \beta=1.4(0.9-2.2) \mathrm{Gy}$,' Int. J. Radiat. Oncol., Biol., Phys. 82, 17-24 (2012).

${ }^{59}$ B. Movsas, J. Chapman, A. Hanlon, E. Horwitz, R. Greenberg, C. Stobbe, G. Hanks, and A. Pollack, "Hypoxic prostate/muscle $\mathrm{pO}_{2}$ ratio predicts for biochemical failure in patients with prostate cancer: Preliminary findings," Urology 60, 634-639 (2002).

${ }^{60}$ B. Movsas, J. Chapman, R. Greenberg, A. Hanlon, E. Horwitz, W. Pinover, C. Stobbe, and G. Hanks, "Increasing levels of hypoxia in prostate carcinoma correlate significantly with increasing clinical stage and patient age: An Eppendorf $\mathrm{pO}_{2}$ study," Cancer 89, 2018-2024 (2000).

${ }^{61}$ J. Jeong, K. Shoghi, and J. Deasy, "Modelling the interplay between hypoxia and proliferation in radiotherapy tumour response," Phys. Med. Biol. 58 4897-4919 (2014)

${ }^{62}$ J. D. Chapman, "Can the two mechanisms of tumor cell killing by radiation be exploited for therapeutic gain?,' J. Radiat. Res. 55, 2-9 (2014).

${ }^{63}$ B. Jones and R. Dale, "Radiobiological compensation of treatment errors in radiotherapy,” Br. J. Radiol. 81, 323-326 (2008).

${ }^{64}$ E. J. Hall, Radiobiology for the Radiologist (Lippincott Williams \& Wilkins, Philadelphia, PA, 2006).

${ }^{65}$ C. Nutting, C. Corbishley, B. Sanchez-Nieto, V. Cosgrave, S. Webb, and D. Dearnaley, "Potential improvements in the therapeutic ratio of prostate cancer irradiation: Dose escalation of pathologically identified tumour nod- ules using intensity modulated radiotherapy,” Br. J. Radiol. 75, 151-161 (2002).

${ }^{66} \mathrm{~S}$. Bentzen, "Theragnostic imaging for radiation oncology: Dose-painting by numbers," Lancet Oncol. 6, 112-117 (2005).

${ }^{67}$ I. Lips, U. van der Heide, K. Haustermans, E. van Lin, F. Pos, S. Franken, A. Kotte, C. van Gils, and M. van Vulpen, "Single blind randomized phase III trial to investigate the benefit of a focal lesion ablative microboost in prostate cancer (FLAME-trial): Study protocol for a randomized controlled trial," Trials 12, 1-11 (2011).

${ }^{68}$ J. Chang, D. Lim Joon, S. Ting Lee, S. Gong, N. Anderson, A. Scott, I. Davis, D. Clouston, D. Bolton, C. Hamilton, and V. Khoo, "Intensity modulated radiation therapy dose painting for localized prostate cancer using ${ }^{11} \mathrm{C}$ choline positron emission tomography scans,' Int. J. Radiat. Oncol., Biol., Phys. 83, e691-e696 (2012)

${ }^{69}$ D. Kelly, R. Jamison, S. Rhoades, and V. Woo, "Dose painting a prostate peripheral zone boost with helical tomotherapy IMRT," Int. J. Radiat. Oncol., Biol., Phys. 84, S405-S406 (2012).

${ }^{70}$ L. Murray, V. Cosgrove, J. Lilley, J. Sykes, C. Thompson, K. Franks, D. Sebag-Montefiore, and A. Henry, "Developing a class solution for prostate stereotactic ablative body radiotherapy (SABR) using volumetric modulated arc therapy (VMAT),' Radiother. Oncol. 110, 298-302 (2014).

${ }^{71}$ L. Murray, J. Lilley, C. Thompson, V. Cosgrove, J. Mason, J. Sykes, K. Franks, D. Sebag-Montefiore, and A. Henry, "Prostate stereotactic ablative radiation therapy using volumetric modulated arc therapy to dominant intraprostatic lesions," Int. J. Radiat. Oncol., Biol., Phys. 89, 406-415 (2014).

${ }^{72}$ N. Bassler, O. Jakel, C. Sondergaard, and J. Petersen, "Dose and LET painting with particle therapy," Acta Oncol. 49, 1170-1176 (2010).

${ }^{73}$ M. Fager, I. Toma-Dasu, M. Kirk, D. Dolney, E. Diffenderfer, N. Vapiwala, and A. Carabe, "Linear energy transfer painting with proton therapy: A means of reducing radiation doses with equivalent clinical effectiveness," Int. J. Radiat. Oncol., Biol., Phys. 91, 1057-1064 (2015).

${ }^{74} \mathrm{H}$. Withers, J. Taylor, and B. Maciejewski, "The hazard of accelerated tumor clonogen repopulation during radiotherapy," Acta Oncol. 27, 131-146 (1988).

${ }^{75} \mathrm{R}$. Wyatt, A. Beddoe, and R. Dale, "The effects of delays in radiotherapy treatment on tumour control," Phys. Med. Biol. 48, 139-155 (2003).

${ }^{76}$ Y. Yang and L. Xing, "Optimization of radiotherapy dose-time fractionation with consideration of tumor specific biology,” Med. Phys. 32, 3666-3677 (2005).

${ }^{77}$ M. Gao, N. Mayr, Z. Huang, H. Zhang, and J. Wang, "When tumor repopulation starts? The onset time of prostate cancer during radiation therapy,' Acta Oncol. 49, 1269-1275 (2010).

${ }^{78}$ H. Akaike, "A new look at the statistical model identification," IEEE Trans. Autom. Control 19, 716-723 (1974).

${ }^{79}$ B. Matthew, S. Williams, and T. Pickles, "Expanded risk groups help determine which prostate radiotherapy sub-group may benefit from adjuvant androgen deprivation therapy," Radiat. Oncol. 3, 1-8 (2008).

${ }^{80}$ A. Dekker, S. Vinod, L. Holloway, C. Oberije, A. George, G. Goozee, G. Delaney, P. Lambin, and D. Thwaites, "Rapid learning in practice: A lung cancer survival decision support system in routine patient care data," Radiother. Oncol. 113, 47-53 (2014).

${ }^{81}$ P. Lambin, J. Zindler, B. Vanneste, L. van de Voorde, M. Jacobs, D. Eekers, J. Peerlings, B. Reymen, R. Larue, T. Deist, E. de Jong, A. Even, A. Berlanga, E. Roelofs, Q. Cheng, S. Carvalho, R. Leijenaar, C. Zegers, E. van Limbergen, M. Berbee, W. van Elmpt, C. Oberije, R. Houben, A. Dekker, L. Boersma, F. Verhaegen, G. Bosmans, F. Hoebers, K. Smits, and S. Walsh, "Modern clinical research: How rapid learning health care and cohort multiple randomised clinical trials complement traditional evidence based medicine," Acta Oncol. 54, 1289-1300 (2015).

${ }^{82}$ M. Roach, G. Hanks, H. Thames, P. Schellhammer, W. Shipley, G. Sokol, and H. Sabdler, "Defining biochemical failure following radiotherapy with or without hormonal therapy in men with clinically localized prostate cancer: Recommendations of the RTOG-ASTRO Phoenix consensus conference,” Int. J. Radiat. Oncol., Biol., Phys. 65, 965-974 (2006).

${ }^{83}$ T. Roland, E. Tryggestad, P. Mavroidis, R. Hales, and N. Papanikolaou, "The radiobiological $\mathrm{P}+$ index for the pretreatment plan assessment with emphasis on four-dimensional radiotherapy modalities," Med. Phys. 10, 6420-6430 (2012).

${ }^{84}$ P. Mavroidis, B. Lind, and A. Brahme, "Biologically effective uniform dose (D) for specification, report and comparison of dose response relations and treatment plans," Phys. Med. Biol. 46, 2607-2630 (2001). 
${ }^{85}$ R. MacKay, P. Graham, C. Moore, J. Logue, and P. Sharrock, "Animation and radiobiological analysis of $3 \mathrm{D}$ motion in conformal radiotherapy," Radiother. Oncol. 52, 43-49 (1999).

${ }^{86}$ D. Fraser, Y. Chen, E. Poon, F. Cury, T. Falco, and F. Verhaegen, "Dosimetric consequences of misalignment and realignment in prostate 3DCRT using intramodality ultrasound image guidance,’ Med. Phys. 37, 2787-2795 (2010).

${ }^{87}$ J. Gora, M. Stock, C. Lutgendorf-Caucig, and D. Georg, "Is there an advantage in designing adapted, patient-specific PTV margins in intensity modulated proton beam therapy for prostate cancer?,' Int. J. Radiat. Oncol., Biol., Phys. 85, 881-888 (2013).

${ }^{88}$ U. Jelen, F. Ammazzalorso, M. Chanrion, S. Graf, K. Zink, R. EngenhartCabillic, and A. Wittig, "Robustness against interfraction prostate move- ment in scanned ion beam radiation therapy,” Int. J. Radiat. Oncol., Biol., Phys. 84, 257-262 (2012).

${ }^{89}$ M. Frese, V. Yu, R. Stewart, and D. Carlson, "A mechanism-based approach to predict the relative biological effectiveness of protons and carbon ions in radiation therapy," Int. J. Radiat. Oncol., Biol., Phys. 83, 442-450 (2012).

${ }^{90}$ M. Kattan, M. Zelefsky, P. Kupelian, P. Scardino, Z. Fuks, and S. Leibel, "Pretreatment nomogram for predicting the outcome of three-dimensional conformal radiotherapy in prostate cancer," J. Clin. Oncol. 18, 3352-3359 (2000).

${ }^{91}$ L. K. Boyd, X. Mao, and Y. J. Lu, "The complexity of prostate cancer: Genomic alterations and heterogeneity," Nat. Rev. Urol. 9, 652-664 (2012). 